\title{
RESEARCH
}

Open Access

\section{Postoperative outcomes of gastric carcinoma with lymphoid stroma}

\author{
Kenichi Iwasaki* (D), Takeshi Suda, Yuki Takano, Yuki Ohno, Erika Yamada, Naoto Okazaki, Kosuke Takahashi, \\ Takafumi Watanabe, Yosuke Makuuchi, Yoshihiro Ota, Yoshiaki Osaka, Akiyoshi Seshimo, Kenji Katsumata and \\ Akihiko Tsuchida
}

\begin{abstract}
Background: Gastric carcinoma with lymphoid stroma (GCLS) is a rare subtype of gastric cancer. There have been several reports demonstrating the favorable prognosis of early GCLS without lymph node metastasis (LNM) compared with gastric adenocarcinomas. However, it remains unknown whether advanced GCLS (AGCLS) with LNM has a similar prognosis and clinicopathological features. This study aimed to assess the clinicopathological features of GCLS of all stages.

Methods: We retrospectively assessed 375 patients who were pathologically diagnosed with gastric cancer and underwent curative surgical resection at Tokyo Medical University, Japan, between September 2013 and October 2019. Of these patients, 357 (95.2\%) patients were pathologically diagnosed with gastric adenocarcinomas, and 18 (4.8\%) patients were diagnosed with GCLS. The GCLS patients $(n=18)$ were compared with the gastric adenocarcinoma patients (non-GCLS patients, control) $(n=357)$ in terms of their clinicopathological features and clinical outcome.

Results: The GCLS patients showed significantly predominant upper gastric locations ( $P=0.003$ ), lower number of $\operatorname{LNM}(P=0.01)$, and better overall survival rate than the non-GCLS patients $(P=0.029)$. The predominant upper gastric locations $(P=0.0002)$, lower number of $\operatorname{LNM}(P=0.003)$, and better overall survival rate $(P=0.04)$ were significantly correlated in the AGCLS with LNM patients compared with the advanced non-GCLS with LNM patients. For survival analyses, surgical procedure, tumor location, and numbers of positive LNM were adjusted by 1:1 propensity score matching. After adjustment, the overall survival rate was significantly higher in the AGCLS group than in the advanced non-GCLS group $(P=0.03)$.

Conclusion: AGCLS has distinct clinicopathological features and clinical behavior that are similar to those of early GCLS. AGCLS with LNM patients showed a significantly lower number of LNM and a better survival rate than advanced non-GCLS with LNM patients. To our knowledge, this study is the first report to describe the clinicopathological features of AGCLS.
\end{abstract}

Keywords: Gastric carcinoma with lymphoid stroma, Gastric cancer, Lymph node

\footnotetext{
*Correspondence: iwa0715@gmail.com

Department of Gastrointestinal and Pediatric Surgery, Tokyo Medical

University, 6-7-1 Nishishinjuku, Shinjuku-ku, Tokyo 160-0023, Japan
}

(c) The Author(s). 2020 Open Access This article is licensed under a Creative Commons Attribution 4.0 International License, which permits use, sharing, adaptation, distribution and reproduction in any medium or format, as long as you give appropriate credit to the original author(s) and the source, provide a link to the Creative Commons licence, and indicate if changes were made. The images or other third party material in this article are included in the article's Creative Commons licence, unless indicated otherwise in a credit line to the material. If material is not included in the article's Creative Commons licence and your intended use is not permitted by statutory regulation or exceeds the permitted use, you will need to obtain permission directly from the copyright holder. To view a copy of this licence, visit http://creativecommons.org/licenses/by/4.0/. The Creative Commons Public Domain Dedication waiver (http://creativecommons.org/publicdomain/zero/1.0/) applies to the data made available in this article, unless otherwise stated in a credit line to the data. 


\section{Background}

Gastric carcinoma with lymphoid stroma (GCLS), which is also known as gastric lymphoepithelioma-like carcinoma, is a rare histological subtype of gastric cancer, the fourth most frequent cancer in the world [1]. It is also called medullary carcinoma or lymphoepithelioma-like carcinoma [2-4]. GCLS accounts for only about $1-4 \%$ of all malignant gastric tumors, and up to $80 \%$ of the reported GCLS cases are associated with an Epstein-Barr virus (EBV) infection [5-8].

Histologically, GCLS is characterized by a high density of tightly packed tumor cells with extensive lymphocytic infiltrations into the surrounding stroma and the tumor itself $[9,10]$. Despite these known histological features, its diagnostic criteria have not been standardized, and its molecular features remain obscure. There have been several reports demonstrating the favorable prognosis of GCLS compared with other gastric adenocarcinomas, as well as its differentiating clinicopathological features [11-16]. With its low frequency of lymph node metastasis (LNM), an expanded indication of endoscopic resection in early GCLS cases has been suggested [17-20]. However, to our knowledge, current information on GCLS including its clinicopathological features, survival outcomes, and treatment remains inadequate with only a few studies owing to its rarity [13]. Moreover, it remains unclear whether advanced GCLS (AGCLS) with LNM patients have a favorable prognosis. Although GCLS is an infrequently encountered subtype of gastric cancer, it is equally relevant to clarify its outcome and clinicopathological features to obtain a better understanding of this rare but important disease.

This study aimed to assess and compare the clinicopathological features and clinical outcomes between GCLS patients and non-GCLS patients, not only in the early stages but also in all the stages, including AGCLS with LNM patients who underwent curative surgical resection in our hospital.

\section{Methods}

We retrospectively assessed 375 patients who were pathologically diagnosed with gastric cancer and underwent curative surgical resection at Tokyo Medical University Hospital, Japan, between September 2013 and October 2019. Of these patients, 357 (95.2\%) patients were pathologically diagnosed with conventional differentiated gastric adenocarcinomas with no GCLS morphology (i.e., nonGCLS patients, control), and 18 (4.8\%) patients were pathologically diagnosed with GCLS (i.e., GCLS patients). In all patients, curative gastrectomy with lymphadenectomy was routinely performed.

The Japanese Classification of Gastric Carcinoma 15th edition [21] was used to diagnose and examine the resected specimens. The gastric carcinomas were classified into stages according to the Union for International Cancer Control classification 8th edition [22]. GCLS was determined as a poorly differentiated or undifferentiated tumor with prominent lymphoid infiltration on the basis of the 2010 World Health Organization classification guidelines [23].

The GCLS patients were compared with the nonGCLS patients in terms of clinicopathological features including factors such as age, sex, treatment outcomes, tumor site, macroscopic type, tumor size, tumor depth, LNM, and lymphovascular invasion which were obtained from the medical chart reviews, histology slides, and pathology reports. All patients were followed up for 5 years, or until death if it came earlier. Figure 1 shows the flow diagram of the patients registered in this study.

\section{Statistical analysis}

Quantitative data were expressed as mean \pm standard deviation (SD). The Kaplan-Meier method was used to determine the cumulative survival rate. The log-rank test was applied to analyze the correlation between the clinicopathological factors and the survival of GCLS and non-GCLS patients. Propensity score matching was used for 1:1 matching to adjust the difference between the two groups. Selected covariables included age, gender, tumor location, chemotherapy, T stage, LNM, and TNM stage. Statistical analysis was performed using SPSS 13.0.

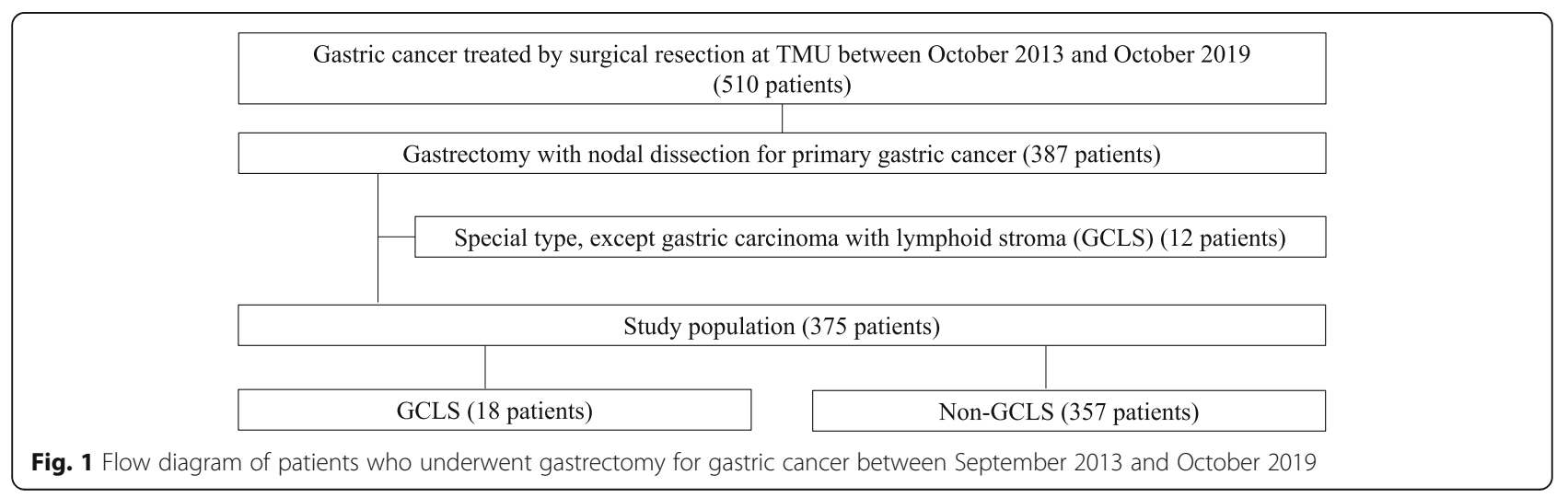


Table 1 Background and clinicopathological features of GCLS and non-GCLS patients

\begin{tabular}{|c|c|c|c|c|}
\hline & & GCLS patients & Non-GCLS patients (control) & $P$ value \\
\hline & & $n=18(\%)$ & $n=357(\%)$ & \\
\hline Age (years, mean $\pm \mathrm{SD}$ ) & & $71 \pm 12.3$ & $72 \pm 11.6$ & 0.60 \\
\hline Gender & & & & 0.70 \\
\hline & Male & $14(77.8)$ & $263(73.7)$ & \\
\hline & Female & $4(22.2)$ & $94(16.3)$ & \\
\hline Surgical procedures & & & & 0.11 \\
\hline & TG & $10(55.6)$ & $108(30.3)$ & \\
\hline & DG & $7(38.9)$ & $221(61.9)$ & \\
\hline & PG & $1(5.6)$ & $19(7.8)$ & \\
\hline Tumor diameter $(\mathrm{mm}$, mean $\pm \mathrm{SD})$ & & $25 \pm 26.9$ & $47.2 \pm 30.8$ & 0.21 \\
\hline Site of tumor & & & & 0.003 \\
\hline & Upper third & $11(61.1)$ & $72(20.2)$ & \\
\hline & Middle third & $4(22.2)$ & $175(49.0)$ & \\
\hline & Lower third & $3(16.7)$ & $110(30.8)$ & \\
\hline Number of tumors & & & & 0.92 \\
\hline & Single & $17(94.4)$ & $329(92.2)$ & \\
\hline & Multiple & $1(5.6)$ & $28(7.8)$ & \\
\hline Macroscopic type & & & & 0.44 \\
\hline & Superficial & $9(50.0)$ & $190(53.2)$ & \\
\hline & Borrmann I1 (5.6) & $19(5.3)$ & & \\
\hline & Borrmann II & $4(22.2)$ & $52(14.6)$ & \\
\hline & Borrmann III & $4(22.2)$ & $68(19.1)$ & \\
\hline & Borrmann IV & $0(0)$ & $13(3.6)$ & \\
\hline & Borrmann V & $0(0)$ & $15(4.2)$ & \\
\hline Tumor invasion & & & & 0.48 \\
\hline & TO & $0(0)$ & $0(0)$ & \\
\hline & $\mathrm{T} 1$ & $11(61.1)$ & $184(51.5)$ & \\
\hline & T2 & $3(16.7)$ & $37(10.4)$ & \\
\hline & T3 & $0(0)$ & $70(19.6)$ & \\
\hline & T4 & $4(22.2)$ & $66(18.5)$ & \\
\hline Number of harvested LN (mean \pm SD) & & $52 \pm 29.4$ & $47.3 \pm 20.5$ & 0.53 \\
\hline LN metastasis & & & & 0.94 \\
\hline & Absent & $11(61.1)$ & $218(61.1)$ & \\
\hline & Present & $7(38.9)$ & $139(38.9)$ & \\
\hline Number of positive LN (mean \pm SD) & & $1.39 \pm 2.43$ & $3.24 \pm 7.8$ & 0.01 \\
\hline Lymphatic invasion & & & & 0.33 \\
\hline & ly0 & $10(55.6)$ & $154(43.1)$ & \\
\hline & ly1 & $2(11.1)$ & $114(31.9)$ & \\
\hline & ly2 & $4(22.2)$ & $52(14.6)$ & \\
\hline & ly3 & $2(11.1)$ & $37(10.4)$ & \\
\hline Vascular invasion & & & & 0.68 \\
\hline & v0 & $10(55.6)$ & $180(50.4)$ & \\
\hline & v1 & $5(27.8)$ & $100(28.0)$ & \\
\hline & v2 & $3(16.7)$ & 55 (15.4) & \\
\hline
\end{tabular}


Table 1 Background and clinicopathological features of GCLS and non-GCLS patients (Continued)

\begin{tabular}{llll}
\hline & & GCLS patients & $\begin{array}{l}\text { Non-GCLS patients (control) } \\
n=357(\%)\end{array}$ \\
\hline \multirow{3}{*}{ Pathological stage } & V3 & $0(0)$ & $22(6.2)$ \\
& I & $10(55.5)$ & $196(54.9)$ \\
& II & $5(27.8)$ & $69(19.3)$ \\
III & $3(17.7)$ & $89(24.9)$ \\
EBV & IV & $0(0)$ & $3(0.8)$ \\
& Positive & $17(94.4)$ & - \\
\hline
\end{tabular}

GCLS gastric carcinoma with lymphoid stroma, SD standard deviation, TG total gastrectomy, DG distal gastrectomy, PG proximal gastrectomy, $L N$ lymph node, EBV Epstein-Barr virus

A $P$ value of $<0.05$ was considered to indicate a statistically significant difference.

\section{Results}

A comparative summary of the background and clinicopathological features of the GCLS patients and nonGCLS patients is shown in Table 1. The GCLS patients consisted of $14(77.8 \%)$ men and 4 women whose age ranged from 48 to 89 years (mean 71 years). Total gastrectomy was the most common surgical procedure $(10 / 18,55.6 \%)$, followed by distal gastrectomy. As shown in Table 1, there was no significant difference in the tumor diameter between the GCLS patients and the non-GCLS patients $(P=0.21)$, although GCLS was found more in proximal locations (upper third 61.1\%/ $20.2 \%, P=0.003$ ). Only one patient out of the 18 GCLS patients showed tumor multiplicity (5.6\%). The most common macroscopic type was superficial $(9 / 18,50 \%)$.

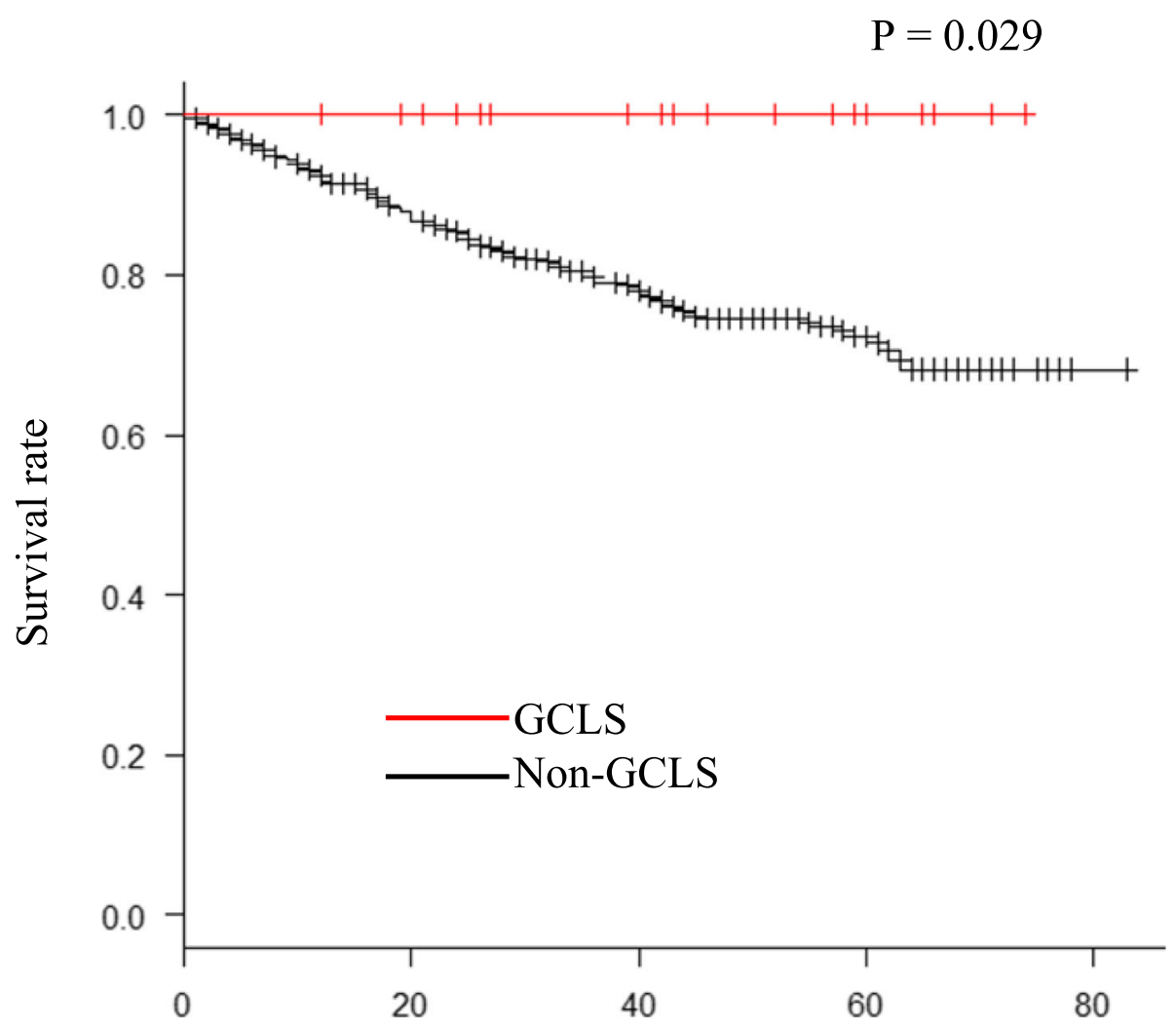

Overall survival (months)

Fig. 2 Kaplan-Meier survival curves of GCLS and non-GCLS patients 
Tumor invasion was most frequent for $\mathrm{T} 1$ (mucosa or submucosa). There was no significant difference in the number of dissected lymph nodes per surgical specimen between the GCLS patients and the non-GCLS patients $(P=0.53)$. However, the GCLS patients were associated with a significantly lower number of LNM $(P=0.01)$. There was no significant difference in the lymphatic or vascular invasion and pathological stage between the two groups. Only one patient was EBV-negative in the GCLS group (EBV positivity was not determined in the control group). There was a significant difference in the overall survival rate between the GCLS patients and the non-GCLS patients (Fig. 2, $P=0.029$ ). The detailed clinicopathological features of each GCLS patient are summarized in Table 2.

A comparative summary of the background and clinicopathological features of AGCLS with LNM patients and advanced non-GCLS with LNM patients (conventional adenocarcinoma with LNM) is shown in Table 3. The AGCLS with LNM patients consisted of 6 (85.7\%) men and 1 woman whose age ranged from 42 to 84 years (mean 72 years). Total gastrectomy was the most frequent surgical procedure in the AGCLC with LNM patients (6 of 7, 85.7\%), which showed a significant difference compared with the advanced non-GCLS with LNM patients $(P=0.03)$. The tumor diameter of the AGCLS with LNM patients was $61.5 \pm 31.5 \mathrm{~mm}$ (mean \pm SD) whereas that of the advanced non-GCLS with LNM patients was $53.1 \pm 31.4(P=0.51)$. As also shown in GCLS, the AGCLS with LNM patients showed predominant upper gastric location compared with the advanced non-GCLS with LNM patients $(P=0.0002)$. Of the 7 AGCLS with LNM patients, one patient showed tumor multiplicity (14.3\%). The most common macroscopic type and tumor invasion were Borrmann III (3/7, $42.8 \%)$ and $\mathrm{T} 4(3 / 7,42.8 \%)$, respectively. There was no significant difference in the number of harvested lymph nodes per surgical specimen between the AGCLS with LNM patients and the advanced non-GCLS with LNM patients $(P=0.63)$. However, the AGCLS with LNM patients were associated with a significantly lower number of LNM $(P=0.003)$. There was no significant difference in the lymphatic or vascular invasion and pathological stage between the two groups. All the AGCLS with LNM patients were EBV-positive (EBV positivity was not determined in the advanced non-GCLS with LNM patients).

There was a significant difference in the overall survival rate between the AGCLS with LNM patients and the advanced non-GCLS with LNM patients (Fig. 3, $P=$ 0.04 ). For the survival analyses, surgical procedure, location, and positive LNM were adjusted by 1:1 propensity score matching. After adjustment, the overall survival rate was significantly higher in the AGCLS group than in the advanced non-GCLS group (Fig. $4, P=0.03$ ).

Table 2 Clinicopathological features of 18 GCLS patients

\begin{tabular}{|c|c|c|c|c|c|c|c|c|c|c|c|c|c|}
\hline Case & Age (yrs) & Sex & Location & Macroscopic type & $\begin{array}{l}\text { No. of } \\
\text { tumors }\end{array}$ & Tumor size (mm) & pT stage & pN stage & $\begin{array}{l}\text { No. of } \mathrm{LN+/} \\
\text { LN total }\end{array}$ & ly & $v$ & pStage & $\begin{array}{l}\text { Surgical } \\
\text { procedure }\end{array}$ \\
\hline 1 & 48 & M & $U$ & $0-\| c$ & 1 & 14 & 1 & 0 & $0 / 45$ & 0 & 0 & I & DG \\
\hline 2 & 64 & M & M & 1 & 1 & 25 & 1 & 0 & $0 / 67$ & 0 & 0 & । & DG \\
\hline 3 & 75 & M & L & $0-\| c$ & 1 & 13 & 1 & 0 & $0 / 54$ & 0 & 0 & । & DG \\
\hline 4 & 55 & M & $U$ & $0-\| c$ & 3 & 24 & 1 & 2 & $4 / 62$ & 0 & 0 & $\|$ & TG \\
\hline 5 & 42 & M & $U$ & 2 & 1 & 25 & 1 & 1 & $2 / 31$ & 0 & 1 & $\|$ & TG \\
\hline 6 & 63 & M & $U$ & 3 & 1 & 100 & 4 & 1 & $2 / 83$ & 2 & 1 & III & TG \\
\hline 7 & 64 & $M$ & U & $0-\| c$ & 1 & 44 & 1 & 0 & $0 / 56$ & 0 & 0 & I & $\mathrm{TG}$ \\
\hline 8 & 74 & F & U & 3 & 1 & 52 & 4 & 1 & $1 / 48$ & 1 & 2 & III & $\mathrm{TG}$ \\
\hline 9 & 89 & $M$ & M & $0-\| c$ & 1 & 16 & 1 & 0 & $0 / 25$ & 0 & 0 & I & DG \\
\hline 10 & 72 & $\mathrm{M}$ & U & 0-Ila & 1 & 20 & 2 & 1 & $2 / 9$ & 2 & 2 & ॥ & $\mathrm{TG}$ \\
\hline 11 & 76 & $F$ & L & 2 & 1 & 50 & 1 & 0 & $0 / 52$ & 2 & 0 & I & DG \\
\hline 12 & 84 & $\mathrm{M}$ & M & 2 & 1 & 76 & 2 & 2 & $5 / 24$ & 3 & 2 & ॥ & DG \\
\hline 13 & 83 & M & U & 2 & 1 & 20 & 2 & 0 & $0 / 11$ & 2 & 1 & I & $\mathrm{TG}$ \\
\hline 14 & 80 & $M$ & U & $0-\| c$ & 1 & 10 & 1 & 0 & $0 / 34$ & 0 & 0 & I & $P G$ \\
\hline 15 & 65 & F & $M$ & 0-lla & 1 & 13 & 1 & 0 & $0 / 52$ & 0 & 0 & I & DG \\
\hline 16 & 65 & M & U & 3 & 1 & 75 & 4 & $3 a$ & $9 / 72$ & 3 & 1 & III & $\mathrm{TG}$ \\
\hline 17 & 70 & F & U & 3 & 1 & 55 & 4 & 0 & $0 / 133$ & 1 & 1 & $\|$ & TG \\
\hline 18 & 75 & $M$ & L & $0-\| c$ & 1 & 65 & 1 & 0 & 0/75 & 0 & 0 & I & $\mathrm{TG}$ \\
\hline
\end{tabular}

$M$ male, $F$ female, $U$ upper third, $M$ middle third, $L$ lower third, No. number, $p$ pathological, $L N$ lymph node, ly lymphatic invasion, $v$ venous invasion, $D G$ distal gastrectomy, $T G$ total gastrectomy, $P G$ proximal gastrectomy 
Table 3 Background and clinicopathological features of AGCLS and non-GCLS with LNM patients

\begin{tabular}{|c|c|c|c|c|}
\hline & & $\begin{array}{l}\text { AGCLS with LNM } \\
\text { patients } n=7(\%)\end{array}$ & $\begin{array}{l}\text { Advanced non-GCLS with LNM } \\
\text { patients } n=139(\%)\end{array}$ & $P$ value \\
\hline Age (years, mean $\pm S D$ ) & & $72 \pm 10.7$ & $65 \pm 13.7$ & 0.19 \\
\hline \multirow[t]{3}{*}{ Gender } & & & & 0.57 \\
\hline & Male & $6(85.7)$ & $107(77)$ & \\
\hline & Female & $1(14.3)$ & $32(23)$ & \\
\hline \multirow[t]{4}{*}{ Surgical procedures } & & & & 0.03 \\
\hline & $\mathrm{TG}$ & $6(85.7)$ & $63(45.3)$ & \\
\hline & DG & $1(14.3)$ & $70(50.3)$ & \\
\hline & $P G$ & $0(0)$ & $6(4.4)$ & \\
\hline Tumor diameter $(\mathrm{mm}$, mean $\pm \mathrm{SD})$ & & $61.5 \pm 31.5$ & $53.1 \pm 31.4$ & 0.51 \\
\hline \multirow[t]{4}{*}{ Site of tumor } & & & & 0.0002 \\
\hline & Upper third & $6(85.7)$ & $36(25.9)$ & \\
\hline & Middle third & $1(14.3)$ & $57(41.0)$ & \\
\hline & Lower third & $0(0)$ & $46(33.1)$ & \\
\hline \multirow[t]{3}{*}{ Number of tumors } & & & & 0.92 \\
\hline & Single & $6(85.7)$ & $130(93.5)$ & \\
\hline & Multiple & $1(14.3)$ & $9(6.5)$ & \\
\hline \multirow[t]{7}{*}{ Macroscopic type } & & & & 0.19 \\
\hline & Superficial & $2(28.6)$ & $33(23.7)$ & \\
\hline & Borrmann I & $0(0)$ & $5(3.6)$ & \\
\hline & Borrmann II & $2(28.6)$ & $34(24.4)$ & \\
\hline & Borrmann III & $3(42.8)$ & $47(33.8)$ & \\
\hline & Borrmann IV & $0(0)$ & $11(7.9)$ & \\
\hline & Borrmann V & $0(0)$ & $9(6.6)$ & \\
\hline \multirow[t]{6}{*}{ Tumor invasion } & & & & 0.57 \\
\hline & T0 & $0(0)$ & $0(0)$ & \\
\hline & $\mathrm{T} 1$ & $2(28.6)$ & $25(18.0)$ & \\
\hline & $\mathrm{T} 2$ & $2(28.6)$ & $16(11.5)$ & \\
\hline & T3 & $0(0)$ & $47(33.8)$ & \\
\hline & T4 & $3(42.8)$ & $51(36.7)$ & \\
\hline Number of harvested LN (mean \pm SD) & & $47.0 \pm 27.0$ & $52.2 \pm 21.4$ & 0.63 \\
\hline Number of positive LN (mean \pm SD) & & $3.57 \pm 2.76$ & $8.28 \pm 10.7$ & 0.003 \\
\hline \multirow[t]{5}{*}{ Lymphatic invasion } & & & & 0.76 \\
\hline & ly0 & $2(28.6)$ & $8(5.8)$ & \\
\hline & ly1 & $1(14.2)$ & $59(42.4)$ & \\
\hline & ly2 & $2(28.6)$ & $37(26.6)$ & \\
\hline & ly3 & $2(28.6)$ & $35(25.2)$ & \\
\hline \multirow[t]{5}{*}{ Vascular invasion } & & & & 0.8 \\
\hline & v0 & $1(14.2)$ & $26(18.7)$ & \\
\hline & v1 & $3(42.9)$ & $54(38.9)$ & \\
\hline & $\mathrm{V} 2$ & $3(42.9)$ & $42(30.2)$ & \\
\hline & v3 & $0(0)$ & $17(12.2)$ & \\
\hline \multirow[t]{2}{*}{ Pathological stage } & & & & 0.41 \\
\hline & 1 & $1(14.2)$ & $17(12.2)$ & \\
\hline
\end{tabular}


Table 3 Background and clinicopathological features of AGCLS and non-GCLS with LNM patients (Continued)

\begin{tabular}{llll}
\hline & & $\begin{array}{l}\text { AGCLS with LNM } \\
\text { patients } n=7(\%)\end{array}$ & $\begin{array}{l}\text { Advanced non-GCLS with LNM } \\
\text { patients } n=139(\%)\end{array}$ \\
\hline & II & $3(42.9)$ & $33(23.8)$ \\
& IV & $3(42.9)$ & $87(62.6)$ \\
Survival after surgery & & $0(0)$ & $2(1.4)$ \\
(Months; mean \pm SD) & & $44 \pm 16.3$ & $28.2 \pm 21.3$ \\
EBV & Positive & & $7(100)$ \\
& Negative & $0(0)$ & - \\
\hline
\end{tabular}

GCLS gastric carcinoma with lymphoid stroma, $S D$ standard deviation, $T G$ total gastrectomy, $D G$ distal gastrectomy, $P G$ proximal gastrectomy, $L N$ lymph node, $E B V$ Epstein-Barr virus

\section{Discussion}

GCLS, also called gastric lymphoepithelioma-like carcinoma, is a rare subtype of gastric carcinoma that shows distinct clinical characteristics compared with conventional adenocarcinoma. In the present study, 18 patients (4.8\%) of the 375 surgically treated gastric carcinoma patients were identified as having GCLS. This frequency is nearly similar to those of previous reports corresponding to $1-4 \%$ of all gastric carcinomas $[6,24,25]$. Although the underlying reason remains unclear, earlier studies showed that GCLS has a favorable prognosis with a low LNM rate [6, 10, 20, 26, 27].

Consistent with previous reports [16, 28, 29], in our series, we found that the GCLS patients showed predominant upper gastric locations and were associated with a significantly lower number of LNM than the nonGCLS patients (conventional adenocarcinoma). Moreover, there was a significant difference in the overall

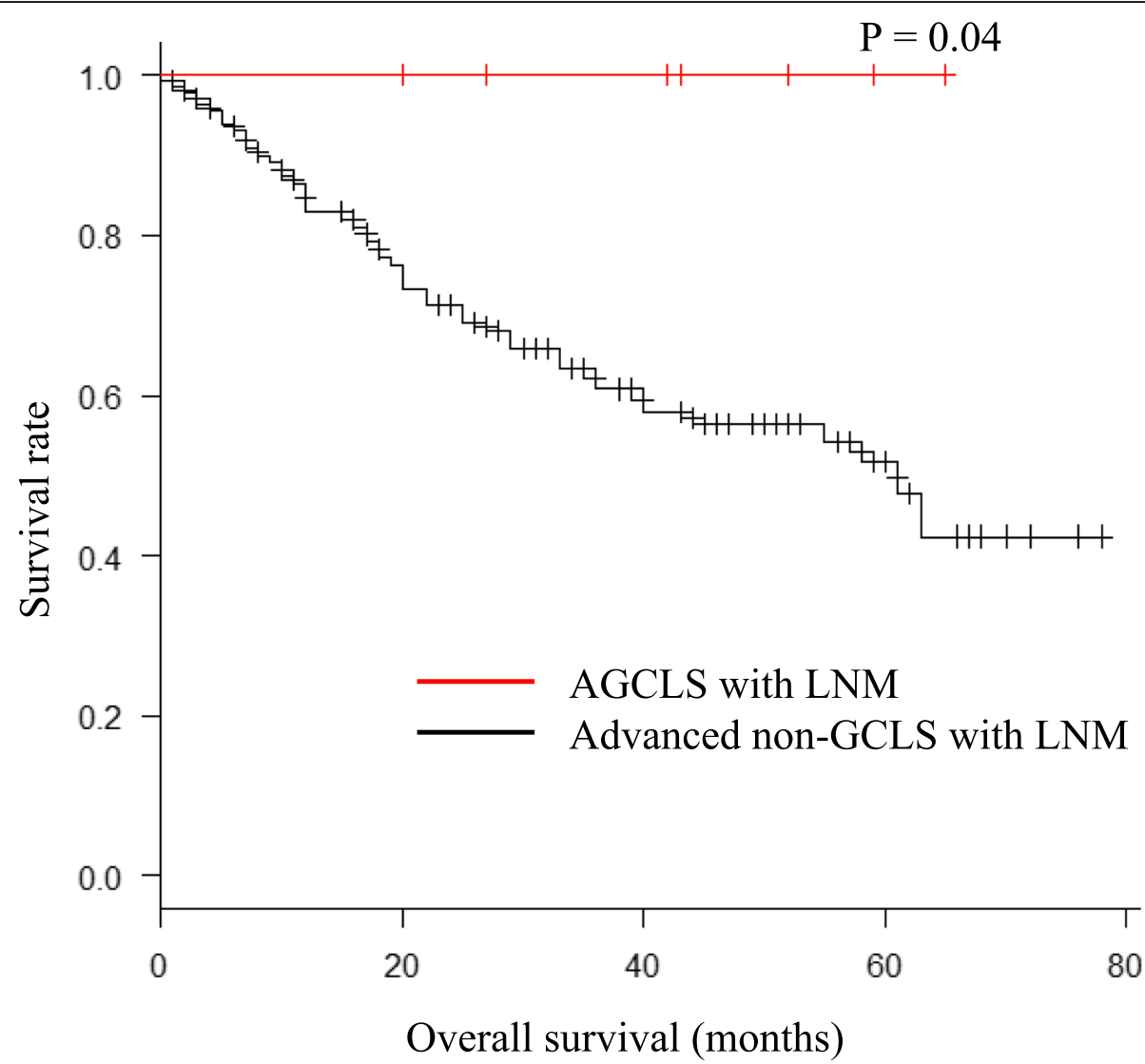

Fig. 3 Kaplan-Meier survival curves of AGCLS with LNM patients and advanced non-GCLS with LNM patients 


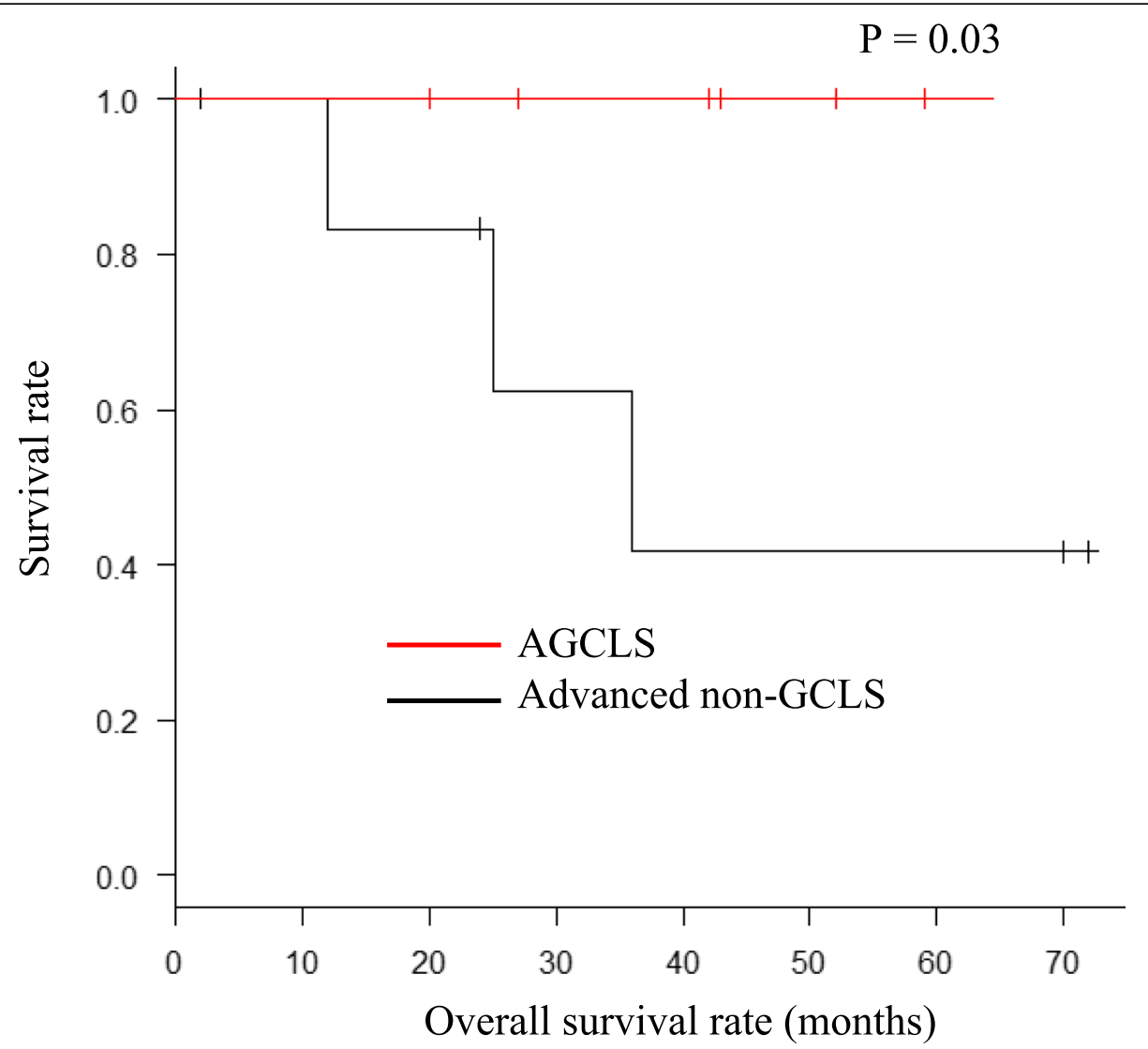

Fig. 4 Overall survival rates after adjustment of location, surgical procedure, and positive LNM using propensity score matching for 1:1 matching

survival rate between the GCLS patients and the nonGCLS patients. To date, several studies have reported that early GCLS has unique features with an extremely low frequency of LNM [20,30]. It has also been reported that the increase in the number of tumor-infiltrating lymphocytes, which reflects the host immune response to tumor cells, was associated with improved survival $[31,32]$. The LNM rate of GCLS patients in the present study was $38.9 \%$ ( $7 / 18$ patients).

Shin et al. reported the clinicopathological features of 70 early GCLS patients and showed an extremely low rate of LNM, as well as the tendency for the macroscopic type, tumor location, and tumor size [30]. With its low likelihood of LNM, endoscopic resection has been suggested as an alternative treatment option for early GCLS patients [17-19]. However, despite the favorable prognosis of early GCLS, it remains unclear whether AGCLS also shows a favorable prognosis and similar clinicopathological features. In the present study, we found that among the AGCLS with LNM patients, total gastrectomy was the most frequent surgical procedure $(6 / 17,85.7 \%)$, which showed a significant difference compared with the advanced non-GCLS with LNM patients $(P=0.03)$. Similarly to the GCLS patients, the
AGCLS with LNM patients showed predominant upper gastric locations compared with the advanced nonGCLS with LNM patients $(P=0.0002)$. Another finding was that, among all the patients with LNM, the AGCLS patients were associated with a significantly lower number of LNM even though there was no difference in the number of LNs harvested and examined $(P=0.003)$. There was no significant difference in the lymphatic or vascular invasion and pathological stage between the two groups. All patients in the AGCLS group were EBVpositive (EBV positivity was not determined in patients in the control group). As shown in the Kaplan-Meier survival curve in Fig. 3, the overall survival rate of the AGCLS with LNM patients was significantly higher than that of the advanced non-GCLS with LNM patients $(P=$ 0.04). As this is apparently the first report to show the long-term follow-up of AGCLS with LNM patients, this finding provides a better understanding of this rare disease. As the surgical procedure, location, and number of LNM were significantly different, we adjusted each factor by $1: 1$ propensity score matching to assess the prognosis and survival of AGCLS with LNM patients and to compare them with those of advanced non-GCLS with LNM patients. 
Interestingly, we found that even after adjustment, the overall survival rate was significantly higher in the AGCLS group than in the advanced non-GCLS group (Fig. 4, $P=0.03$ ). Some studies have reported that less LNM is a factor for good prognosis in GCLS [7, 15, 29]. However, the present findings indicate that further studies are warranted to fully clarify the clinical and histological features of GCLS that are associated with a good prognosis $[4,18,22]$.

Kim et al. reported the association between the sizes of the gastric carcinoma and LNM [33]. In their study, the tumor size was the only significant risk factor for LNM in the analysis of 574 patients. However, in the present study, there was no significant difference in the size of the tumor between the AGCLS with LNM patients and the advanced non-GCLS with LNM patients.

In their report of 40 GCLS patients, Lim et al. (2018) suggested that endoscopic resection without LN dissection could be an alternative option for early gastric cancer with lymphoid stroma patients [34]. Our results of 18 GCLS patients also showed an extremely good survival rate after surgery, although one patient had recurrence even if the tumor stage was IB and with only one LNM. According to this finding, surgical resection with radical LN dissection may contribute to the good prognosis of GCLS patients even if they have a low risk of LNM. On the other hand, we cautiously suggest that GCLS may be a good candidate for not performing adjuvant chemotherapy, which is a standard therapy for stages II and III gastric cancer in Japan.

Our study has several limitations as follows. The analysis had a retrospective nonrandomized design, the sample size of the GCLS group was small, and the follow-up period after surgery was relatively short in some cases. There were no patients with stage IV tumor in the GCLS group. This was likely due to the small sample size which could have led to some biases. Evaluation of the EBV status of the non-GCLS patients was not performed. Moreover, it remains unclear whether the good prognosis of the GCLS patients is due to the role of EBV.

\section{Conclusion}

AGCLS with LNM has distinct clinicopathological features and clinical behavior that are similar to those of early GCLS. AGCLS with LNM patients showed a significantly lower number of LNM and a better survival rate than advanced non-GCLS with LNM patients. An accurate diagnosis and recognition of GCLS, as well as detailed studies of GCLS based on a larger number of patients are warranted to a further enhance the efficacy of existing treatments or to developed novel treatments for GCLS.

\section{Abbreviations}

GCLS: Gastric carcinoma with lymphoid stroma; LNM: Lymph node metastasis; AGCLS: Advanced GCLS with LNM; EBV: Epstein-Barr virus

\section{Acknowledgements}

We thank Dr. Edward Barroga (https://orcid.org/0000-0002-8920-2607), Medical Editor and Professor of Academic Writing at St. Luke's International University, Tokyo, Japan for reviewing and editing the manuscript.

\section{Authors' contributions}

$\mathrm{KI}$ wrote the paper. $\mathrm{YT}, \mathrm{YO}, \mathrm{EY}, \mathrm{NO}, \mathrm{KT}$, and $\mathrm{YM}$ collected the data and reports in the literature for the article. KI, TS, TW, and YO analyzed and interpreted the data. YO, AS, KK, and AT revised the manuscript for important intellectual content. All authors read and approved the final manuscript.

\section{Funding}

This study received no funding.

\section{Availability of data and materials}

The datasets generated and/or analyzed during the current study are available from the corresponding author on reasonable request.

\section{Ethics approval and consent to participate}

This study was approved by the Ethics Committee of Tokyo Medical University (approval No. T2019-0462).

\section{Consent for publication}

Not applicable.

\section{Competing interests}

The authors declare that they have no competing interests.

Received: 28 March 2020 Accepted: 13 May 2020

Published online: 21 May 2020

\section{References}

1. Van Cutsem E, Sagaert X, Topal B, Haustermans K, Prenen H. Gastric cancer. Lancet. 2016;388:2654-64.

2. Minamoto T, Mai M, Watanabe K, Ooi A, Kitamura T, Takahashi Y, et al. Medullary carcinoma with lymphocytic infiltration of the stomach. Clinicopathologic study of 27 cases and immunohistochemical analysis of the subpopulations of infiltrating lymphocytes in the tumor. Cancer. 1990; 66:945-52.

3. Davessar K, Pezzullo JC, Kessimian N, Hale JH, Jauregui HO. Gastric adenocarcinoma: prognostic significance of several pathologic parameters and histologic classifications. Hum Pathol. 1990;21:325-32.

4. Wu MS, Shun CT, Wu CC, Hsu TY, Lin MT, Chang MC, et al. Epstein-Barr virus-associated gastric carcinomas: relation to $\mathrm{H}$. pylori infection and genetic alterations. Gastroenterology. 2000;118:1031-8.

5. Nakamura S, Ueki T, Yao T, Ueyama T, Tsuneyoshi M. Epstein-Barr virus in gastric carcinoma with lymphoid stroma. Special reference to its detection by the polymerase chain reaction and in situ hybridization in 99 tumors, including a morphologic analysis. Cancer. 1994;73:2239-49.

6. Takada K. Epstein-Barr virus and gastric carcinoma. Mol Pathol. 2000;53:25561.

7. Murphy G, Pfeiffer R, Camargo MC, Rabkin CS. Meta-analysis shows that prevalence of Epstein-Barr virus-positive gastric cancer differs based on sex and anatomic location. Gastroenterology. 2009;137:824-33.

8. Corvalan A, Ding S, Koriyama C, Carrascal E, Carrasquilla G, Backhouse C, et al. Association of a distinctive strain of Epstein-Barr virus with gastric cancer. Int J Cancer. 2006;118:1736-42.

9. Horiuchi K, Mishima K, Ohsawa M, Aozasa K. Carcinoma of stomach and breast with lymphoid stroma: localisation of Epstein-Barr virus. J Clin Pathol. 1994;47:538-40.

10. Song HJ, Srivastava A, Lee J, Kim YS, Kim KM, Ki Kang W, et al. Host inflammatory response predicts survival of patients with Epstein-Barr virusassociated gastric carcinoma. Gastroenterology. 2010;139:84-92.

11. Lee JH, Kim SH, Han SH, An JS, Lee SL, Kim YS. Clinicopathological and molecular characteristics of Epstein-Barr virus-associated gastric carcinoma: a meta-analysis. Gastroenterol Hepatol. 2009;24:354-65. 
12. Lim H, Lee IS, Lee JH, Park YS, Kang HJ, Na HK, et al. Clinical application of early gastric carcinoma with lymphoid stroma based on lymph node metastasis status. Gastric Cancer. 2017;20:793-801.

13. Shibata D, Tokunaga M, Uemura Y, Sato E, Tanaka S, Weiss LM. Association of Epstein-Barr virus with undifferentiated gastric carcinomas with intense lymphoid infiltration. Lymphoepithelioma-like carcinoma. Am J Pathol. 1991; 139:469-74.

14. Shibata D, Weiss LM. Epstein-Barr virus-associated gastric adenocarcinoma. Am J Pathol. 1992;140:769-74.

15. Park S, Choi MG, Kim KM, Kim HS, Jung SH, Lee JH, et al. Lymphoepithelioma-like carcinoma: a distinct type of gastric cancer. I Surg Res. 2015;194:458-63.

16. Okamura T, Kodama Y, Kamegawa T, Sano C, Kumashiro R, Inokuchi K. Gastric carcinoma with lymphoid stroma: correlation to reactive hyperplasia in regional lymph nodes and prognosis. Jpn J Surg. 1983;13:177-83.

17. Lee HL, Kim DC, Lee SP, Lee KN, Jun DW, Lee OY, et al. Treatment of Epstein-Barr virus-associated gastric carcinoma with endoscopic submucosal dissection. Gastrointest Endosc. 2012;76:913-5.

18. Tang SJ, Ahmed N, Bhaijee F, Sheehan J, Subramony C, Jackson C, et al. Endoscopic mucosal resection of an Epstein-Barr virus-associated lymphoepithelioma-like gastric carcinoma. Dig Dis Sci. 2012;57:3032-4.

19. Lee JY, Kim KM, Min BH, Lee JH, Rhee PL, Kim JJ. Epstein-Barr virusassociated lymphoepithelioma-like early gastric carcinomas and endoscopic submucosal dissection: case series. World J Gastroenterol. 2014;20:1365-70.

20. Watanabe H, Enjoji M, Imai T. Gastric carcinoma with lymphoid stroma. Its morphologic characteristics and prognostic correlations. Cancer. 1976;38:232-43.

21. Association JGC. Japanese classification of gastric carcinoma. 15th ed. Tokyo: Kanehara Publisher; 2017

22. Control UIC. TNM classification of malignant tumors. 8th ed. New York: Wiley; 2017.

23. Lauwers GY, Carneiro F, Graham DY, Curado MP, Franceschi S, Montgomery E. Gastric carcinoma. In: Bowan FT, Carneiro F, Hruban RH, Theise ND, editors. WHO classification of tumors of digestive system. 4th ed. Lyon: IARC; 2010. p. 48-58

24. Fukuyama M, Ushiki T. Epstein-Barr virus-associated gastric carcinoma. Pathol Res Pract. 2011;207:529-37.

25. Cheng N, Hui DY, Liu Y, Zhang NN, Jiang Y, Han J, et al. Is gastric lymphoepithelioma-like carcinoma a special subtype of EBV-associated gastric carcinoma? New insight based on clinicopathological features and EBV genome polymorphisms. Gastric Cancer. 2015;18:246-55.

26. van Beek J, Zur Hausen A, Klein Kranenbarg E. EBV-positive gastric carcinomas: a distinct clinicopathologic entity with a low frequency of lymph node involvement. J Clin Oncol. 2004;22:664-70.

27. Cho HJ, Kim JY, Yoo J. Gastric carcinoma with lymphoid stroma: incidence of EBV and Helicobacter pylori infection. Appl Immunohistochem Mol Morphol. 2003;11:149-52

28. Kobayashi R, Takiguchi N, Nabeya Y, Ikeda A, Souda H, Kainuma O, et al. Treatment strategy for gastric carcinoma with lymphoid stroma. Gan To Kagaku Ryoho. 2015;42:2021-3.

29. Lim H, Park YS, Lee JH, Son DH, Ahn JY, Choi KS, et al. Features of gastric carcinoma with lymphoid stroma associated with Epstein-Barr virus. Clin Gastroenterol Hepatol. 2015;10:1738-44.

30. Shin DH, Kim GH, Lee BE, Lee JW, Ha DW, Jeon HK, et al. Clinicopathologic features of early gastric carcinoma with lymphoid stroma and feasibility of endoscopic submucosal dissection. Surg Endosc. 2017;31:4156-64.

31. Japanese Gastric Cancer Association. Japanese gastric cancer treatment guidelines 2014 (ver. 4). Gastric Cancer. 2017;20:1-19,

32. Grogg KL, Lohse CM, Pankratz VS, Halling KC, Smyrk TC. Lymphocyte-rich gastric cancer: associations with Epstein-Barr virus, microsatellite instability, histology, and survival. Mod Pathol. 2003;7:641-51.

33. Kim TJ, Lee H, Min YW, Min BH, Lee JH, Kim KM, et al. One-dimensional and 2-dimensional tumor size measurement for prediction of lymph node metastasis in differentiated early gastric with minute submucosal invasion. Gastrointest Endosc. 2017;85:730-6.

34. Lim H, Lee JH, Park YS, Na HK, Ahn JY, Kim DH, et al. A single-center experience of endoscopic resection for early gastric cancer with lymphoid stroma. J Gastric Cancer. 2018;18:400-8.

\section{Publisher's Note}

Springer Nature remains neutral with regard to jurisdictional claims in published maps and institutional affiliations.

\section{Ready to submit your research? Choose BMC and benefit from}

- fast, convenient online submission

- thorough peer review by experienced researchers in your field

- rapid publication on acceptance

- support for research data, including large and complex data types

- gold Open Access which fosters wider collaboration and increased citations

- maximum visibility for your research: over $100 \mathrm{M}$ website views per year

At BMC, research is always in progress.

Learn more biomedcentral.com/submissions 